\title{
The Establishment of Professional Identity among Educational Technology Graduates in China: A Grounded Theory Study
}

\author{
Shixiao Wang, Shanshan Yang, Ming Chen, Xiaoling Ye* \\ School of Educational Science, Nanjing Normal University, Nanjing, China \\ Email: *yxlheart@126.com
}

How to cite this paper: Wang, S. X., Yang, S. S., Chen, M., \& Ye, X. L. (2021). The Establishment of Professional Identity among Educational Technology Graduates in China: A Grounded Theory Study. Chinese Studies, 10, 241-255.

https://doi.org/10.4236/chnstd.2021.104015

Received: November 1, 2021

Accepted: November 27, 2021

Published: November 30, 2021

Copyright $\odot 2021$ by author(s) and Scientific Research Publishing Inc. This work is licensed under the Creative Commons Attribution International License (CC BY 4.0).

http://creativecommons.org/licenses/by/4.0/

\section{(c) (i) Open Access}

\begin{abstract}
The formation and development of professional identity are affected by many factors. Clarifying the influencing factors of Educational Technology graduates' professional identity plays an important role in improving the quality of talent training. Based on the basic principles of grounded theory, this study takes the undergraduates of educational technology in a Chinese university as an example, and analyzes the main factors affecting the establishment of professional identity. It includes "whether students' expectations of the major are consistent with the reality" and "whether they are satisfied with the status quo". And then this study constructs the cause model of professional identity. It is suggested to improve the professional identity of educational technology graduates from four aspects: 1) Establishing objective professional cognition;

2) Rationalizing curriculum; 3) Strengthening career planning and guidance;

4) Cultivating students' independent ideas and improving self-confidence.
\end{abstract}

\section{Keywords}

Educational Technology Graduates, Construction of Professional Identity, Grounded Theory, Qualitative Research

\section{Introduction}

Educational technology, as a new interdisciplinary subject, is developing vigorously in China. However, it has run up against a barrier of professional identity. Professional identity is the harmonious unity of individuals who like their major, choose a career according to their major and recognize the value of their major (An \& Jia, 2006). Students majoring in educational technology do not have high professional identity before enrollment, and most of the Chinese educational 
technology undergraduates do not know what "educational technology" means when filling out the application, or have a vague understanding, or even misunderstanding. Upon graduation, Chinese fresh graduates majoring in educational technology also show three different forms, namely: First, they have a high degree of professional identity in educational technology, have made clear their future after graduation, or are working hard to achieve the established goals. Second, they are not interested in the major of educational technology and feel confused, wandered and dissatisfied with the current situation and future. Third, students who have excellent academic performance in educational technology major plan to work in other majors or choose to take the postgraduate entrance examination of a different major.

In China, there are many other university disciplines facing the same dilemma. The lack of professional identity not only affects Chinese students' enthusiasm for learning and future career choice, but also affects the efficiency and quality of talent training in Chinese universities and colleges. From the perspective of the educational technology major, this research analyzes why students have different professional identities under the same professional training mode. The research hopes to find effective measures to enhance students' professional identity, in order to provide an effective path for the benign development of Chinese colleges and universities.

\section{Literature Review}

\subsection{Research on the Concept of Professional Identity}

In the early years, scholars believed that professional identity was a part of self-identity, and a process of internalization of individual value and formation of self-image (Levinson et al., 1998; Chen et al., 2008). Until recently, professional identity has been regarded as a dynamic process accompanying the individual learning process, in which the individual's cognition level of the major is the basis, and the difference in cognition will lead to different changes in emotion, which will be reflected in the individual behavior (Wang \& Liu, 2007). The premise of establishing professional identity is whether the importance of professional practice can be reflected, which also indirectly explains the necessity of establishing students' professional identity during an undergraduate period (Tahim, 2015). To sum up, professional identity can stimulate students' recognition of the value of their major, promote students' awareness of accepting their major, and lay a solid professional foundation.

Although academic circles have different understandings of professional identity, it tends to be a dynamic and multi-dimensional structure. Many scholars have explored the influencing factors of professional identity. For example, Liu (2018) found that a number of factors, such as school training objectives, campus culture, curriculum setting, teachers and educational practice, would positively affect the level of professional identity. Wang et al. (2011) analyzed students' professional cognition based on whether students can accurately and 
clearly describe their major to others, and found that enrollment motivation is an important factor that directly affects students' learning behavior and attitude after enrollment.

\subsection{Research on the Influencing Factors of Students' Professional Identity in Educational Technology}

The academic circles have also made a lot of explorations on the professional identity of educational technology students. Han \& Tang (2011) conducted a questionnaire survey on 70 students majoring in educational technology, and studied the professional beliefs of students majoring in educational technology from three aspects: curriculum belief, employment belief and professional identity belief, as well as the corresponding reconstruction strategies. Zhu et al. (2018) conducted a questionnaire survey on the status of professional identity of 464 students majoring in educational technology in a Chinese university, and the results showed that the status of professional identity of Chinese students majoring in educational technology was not good, with significant grade differences. As a whole, educational technology is characterized by "clear professional ideal, ordinary professional reality and fuzzy professional path". Li et al. (2016) found that Chinese educational technology undergraduates learned technical professional knowledge in their junior year and gradually increased their interest in the major. Wang (2003) analyzed the orientation and ability structure of professional identity of educational technology students in Higher Vocational Colleges, believed that the establishment degree of professional identity was closely related to employment, and put forward the need for professional setting and construction for some posts in the society.

It can be seen that most existing studies adopt the quantitative research paradigm and study the main factors affecting professional identity through questionnaires and other methods. It can be seen that most of the existing studies adopt the quantitative research paradigm and discuss the main factors affecting Chinese undergraduates' professional identity through the analysis of scale data from a macro perspective. However, questionnaire survey or experimental data cannot present the long process of ideological change from the ignorant freshman admission to the gradually clear development interest and the final decision on whether to continue to engage in the related work of this major. In other words, compared with macro analysis, this research question is more suitable to start from a micro perspective and go deep into the inner thoughts of individual students to understand the dynamic process of their professional identity establishment. Therefore, this study uses the grounded theory method to analyze the graduation students of Educational technology major in China and explore the process of their professional identity construction. Further, this paper analyzes the reasons and influencing factors for the different degrees of professional identity construction of students in basically the same training environment, in order to provide some reference for the training of talents in the field of educational technology. 


\section{Research Design}

\subsection{Research Methods and Tools}

This study adopted the grounded theory research method in the qualitative research paradigm. Grounded theory is a famous theoretical construction method proposed by Glaser and Strauss. It is a qualitative research method to establish substantial theory from bottom to top. The method of grounded theory refers to finding the core concepts that reflect social phenomena after systematically collecting data, and constructing the corresponding social theory through the relationship between concepts (Chen, 1999). "Coding" in grounded theory refers to the conceptualization of data through continuous comparison of events to events, events to concepts, and concepts to concepts, in order to form categories and their attributes (Strauss \& Corbin, 1990). The coding methods of programmatic grounded theory are divided into open coding, spindle coding and selective coding. In the specific data analysis stage, this study used Nvivo11 software to sort out and analyze the complicated interview data. NVivo11 is one of the powerful computer aided analysis software for qualitative research, which has a strong advantage in the process of data analysis of qualitative materials.

\subsection{Research Objects and Samples}

This study selected senior undergraduates majoring in educational technology from a university in East China as the main research object. Compared with other universities in China, the educational technology major in this university has a long histor, and the school conditions, curriculum training, and teachers are at a better level. Taking this university as a sample, this study hoped to mainly explore the subjective reasons of students in the process of establishing professional identity.

Based on the connotation analysis of professional identity, this study defined two types of case studies. One is the case of "high degree of professional identity construction", and the other is the case of "low degree of professional identity construction". Students with high degree of professional identity construction have clear professional learning objectives, strong executive power and active performance in daily learning. They like to read books related to their major and actively follow their teachers to participate in practical projects. At the same time, these students can recognize the value of educational technology major, have strong confidence in their career prospects, have clear goals for their future life planning, and plan to engage in related work in this major. On the contrary, students with low professional identity construction have no clear professional learning objectives regardless of their learning ability. They do not recognize the value of the educational technology major and do not plan to pursue careers related to their major. However, the low degree of professional identity construction does not mean failure.

This study adopted purposeful sampling to select specific interviewees. In this study, students with "high degree of professional identity construction" and "low 
degree of professional identity construction" were selected to conduct qualitative research through typical cases. 32 eligible students were interviewed voluntarily. Before the interview, the study signed informed consent with the interviewees to ensure that the interviewees were willing to accept the interview and recording, and promised to keep their identity confidential. After the study, the relevant information was handled in a manner that respected the wishes of the interviewees.

Before the formal study, this study used the professional identity questionnaire to conduct a preliminary survey on the status quo of educational technology undergraduates' professional identity. Referring to previous studies, the questionnaire divides professional identity into four dimensions: professional cognition, professional affection, professional behavior and professional training. Based on the pre-survey results, the study was sampled according to the principle of maximum differentiation. Starting with the seventh respondent, this study found that the feelings of the subsequent respondents were basically the same as those of the previous respondents. Based on this, the research reached the state of "data saturation", so 10 interviewees were finally determined (as shown in Table 1).

\section{Interview and Coding Analysis}

The data of this study were collected mainly through in-depth interviews. The data were analyzed using grounded theory coding procedure. After each interview, the researchers fine-tuned the interview outline. The first round of interviews came to an end after the formation of preliminary data saturation. After the first round of interviews, the research team conducted open coding to form preliminary categories, attributes and dimensions, and supplemented and expanded the categories, attributes and dimensions by further enriching the interview data. After theoretical saturation was reached, the interview was ended and spindle coding and open coding were carried out.

Table 1. Basic information of interviewees.

\begin{tabular}{cccl}
\hline Students' ID & Grade & Professional ability & \multicolumn{1}{c}{ Result of construction } \\
\hline T001 & Senior & Strong & High degree (study abroad) \\
T002 & Senior & Medium & High degree (transfer from another major to this major) \\
T003 & Senior & Strong & High degree (continue to pursue graduate studies in this field) \\
T004 & Senior & Strong & High degree (become a middle school information technology teacher) \\
T005 & Senior & Medium & High degree (become a middle school information technology teacher) \\
T006 & Senior & Strong & Low degree (pursue graduate studies in other fields) \\
T007 & Senior & Strong & Low degree (pursue graduate studies in other fields) \\
T008 & Senior & Medium & Low degree (lack of purpose and confidence) \\
T009 & Senior & Medium & Low degree (fail in the postgraduate entrance examination and work in an \\
education company)
\end{tabular}




\subsection{Interview}

In this study, semi-structured interviews were used to communicate with interviewees. Due to the restrictions of the COVID-19, all interviews were conducted online. Before the interview, the researcher introduced the connotation of professional identity to each interviewee, so that they could have a preliminary understanding of the issues related to professional identity, which could better clarify their personal situation and ensure the validity of the interview results. The outline of the interview mainly focuses on the following four aspects: "expectation of the major before enrollment", "opinion of the major course arrangement", "understanding of this major" and "whether the future career choice is related to this major". Under the guidance of the interview outline, the interviewees recalled and described the psychological process of professional identity construction and other related issues. During the interview, the researcher carefully listened to the answers of the interviewees, gave certain responses and suggestions, and helped the interviewees find out the details that confused them. In addition, the researcher gave full respect to the subjects with low professional identity construction. The whole interview process was recorded to ensure the accuracy and completeness of the interview materials.

\subsection{Coding Analysis}

In this study, iflyhear software was used to convert audio recordings into interview texts, and the transcripts were proofread and corrected by two researchers. Then, the research adopted content analysis method based on grounded theory to import the interview data into the "internal materials" of Nvivo11.0 software and encode the text. This study adopted the coding operation process of Chen Xiangming (Chen, 2015), which is the localized improvement of Strauss and Corbin's three-level coding program.

\subsubsection{Open Coding}

In open coding, researchers need to set up presets, conceptualize and abstract data, and constantly compare to form concepts or categories. According to the degree of refinement, open coding can be divided into dimension, attribute and category. Table 2 shows some genera formed after the first-level coding in this study.

\subsubsection{Axial Coding}

On the basis of open coding, axial coding constantly reads the formed concepts repeatedly and establishes the relationship between concepts (Chen, 1999). There are many ways to associate genera. In this study, A coding paradigm model "A) Causal condition-B) Phenomenon-C) Context-D) Intermediary conditionE) Action/interaction strategy-F) Outcome" was used to connect genera and subgenera to enrich genera and recombine data (see Table 3).

\subsubsection{Selective Coding}

Finally, selective coding was carried out, including checking the original data, 
Table 2. An example of open coding for professional identity interviews.

\begin{tabular}{|c|c|c|}
\hline Generic & Attribute & Dimensions \\
\hline \multirow{4}{*}{$\begin{array}{l}\text { Anticipation } \\
\text { and expectation }\end{array}$} & Professional status & $\begin{array}{l}\text { The name of the major is hard to identify; little publicity; low professional } \\
\text { achievement; lack of professional theory system; the COVID-19 becomes an } \\
\text { opportunity for major development... }\end{array}$ \\
\hline & $\begin{array}{l}\text { The status of information } \\
\text { technology teachers }\end{array}$ & $\begin{array}{l}\text { Tedious work; class is easy to be occupied by other teachers; subjects are not } \\
\text { valued... }\end{array}$ \\
\hline & Professional prospects & $\begin{array}{l}\text { Employment advantage brought by the background of computer science; more } \\
\text { employment options; narrow employment direction; students have strong } \\
\text { teaching ability; low recognition; professional niche; Employment competition } \\
\text { with other majors... }\end{array}$ \\
\hline & Professional recognition & $\begin{array}{l}\text { Few entry channels; serious gender discrimination in employment; the major } \\
\text { does not meet the social needs; college entrance examination does not test } \\
\text { information technology... }\end{array}$ \\
\hline \multirow{3}{*}{$\begin{array}{l}\text { Curriculum learning } \\
\text { and training program }\end{array}$} & Curriculum learning & $\begin{array}{l}\text { Search the Internet when encountering learning difficulties; try to learn best } \\
\text { even if don't like it; study is to cope with exams; code porter; can't solve prob- } \\
\text { lems with knowledge; loss of learning enthusiasm... }\end{array}$ \\
\hline & Training program & $\begin{array}{l}\text { Unclear objectives; inaccurate professional positioning; insufficient technical } \\
\text { courses; the course content lags behind and there are few cutting-edge courses... }\end{array}$ \\
\hline & Teaching guidance & $\begin{array}{l}\text { Teaching can be combined with reality; teach principles before teaching codes; } \\
\text { the effect of demonstration teaching in technical courses is good; imitation } \\
\text { before practice; completely self-study can not meet the requirements... }\end{array}$ \\
\hline \multirow{3}{*}{ External factors } & Parental influence & $\begin{array}{l}\text { Help fill in the major; hope that children can be teachers; think girls are suita- } \\
\text { ble to be teachers; ignoring professional choices... }\end{array}$ \\
\hline & Influence of seniors & $\begin{array}{l}\text { Organize practical communication meetings; share the experience of looking } \\
\text { for a job; enthusiasm; helpful... }\end{array}$ \\
\hline & $\begin{array}{l}\text { Influence of } \\
\text { classmates and friends }\end{array}$ & $\begin{array}{l}\text { Ask students who are good at programming for help; get along well; in a good } \\
\text { state of life; try postgraduate entrance examination... }\end{array}$ \\
\hline \multirow{3}{*}{ Self cognition } & Hobby & Do not like sports; interested in programming courses; like being a teacher... \\
\hline & Personal Specialty & Have the foundation of painting; good at designing games; be patient... \\
\hline & Life expectation & $\begin{array}{l}\text { Want to be a teacher in the future; want to engage in educational } \\
\text { administration; enter the company... }\end{array}$ \\
\hline
\end{tabular}

Table 3. Axial coding of professional identity interview.

\begin{tabular}{ll}
\hline \multicolumn{1}{c}{ Step } & \multicolumn{1}{c}{ Context } \\
\hline A) Causal condition & $\begin{array}{l}\text { Anticipation and expectation; professional status; current } \\
\text { situation of information technology teachers }\end{array}$ \\
B) Phenomenon & Questioning professional prospects \\
C) Context & Curriculum learning and development program \\
D) Intermediary condition & External factors; self cognition \\
E) Action/interaction & Continue to engage in work related to this major; graduate \\
strategy & school; change careers \\
F) Outcome & Professional identity construction (high degree-low degree) \\
\hline
\end{tabular}


exploring the relationship between the formed genera, and extracting the core genera. The study found that the main factors affecting the construction of professional identity of undergraduate students are "whether the expectation is consistent with the reality" and "whether the personality is content with the status quo" (see Table 4).

\section{Findings and Discussions}

\subsection{Major Influencing Factors of Educational Technology Undergraduates' Professional Identity in China}

Based on the grounded analysis of the interview data, it is found that whether students' expectation of their major is consistent with the reality and whether they are satisfied with the current situation and unwilling to move forward are the two main factors that affect students' establishment of professional identity.

\subsubsection{Consistency between Expectation and Reality Is the Fundamental Reason Affecting Professional Identity}

Based on the original interview texts and coding results (see Table 4), this study found that Chinese educational technology undergraduates located their sense of "consistency" in the comparison between their own expectations and reality. The following five factors directly lead to whether students' expectations of educational technology major are in line with their expectations: current status of the major, course learning, training program, social recognition of the major and external factors.

From the perspective of the current status of the major, whether the current development of the major is bright or dim is a subjective feeling for students, which is more derived from the subtle influence of teachers and the positioning generated by their own psychological comparison.

From the perspective of course learning, when students get a sense of achievement from learning, they will have a strong professional identity. However, the solidness of curriculum learning and the acquisition of a sense of achievement are not only related to the students' own efforts, but also related to whether the

Table 4. Selective coding of professional identity interview.

\begin{tabular}{|c|c|c|}
\hline Core genera & Secondary genera & Dimension \\
\hline \multirow{5}{*}{$\begin{array}{l}\text { Whether the } \\
\text { expectation is } \\
\text { consistent with the } \\
\text { reality }\end{array}$} & Professional status & Light_-Dark \\
\hline & Curriculum learning & Solid-Not solid \\
\hline & Training program & Satisfaction-Disappointment \\
\hline & Professional recognition & High—Low \\
\hline & Teaching guidance & Fit-Not fit \\
\hline \multirow{3}{*}{$\begin{array}{l}\text { whether the } \\
\text { personality is content } \\
\text { with the status quo }\end{array}$} & Anticipation and expectation & High-Low \\
\hline & External factors & $\begin{array}{l}\text { Strong interference-Weak } \\
\text { interference }\end{array}$ \\
\hline & Self cognition & Clear-Fuzzy \\
\hline
\end{tabular}


teachers' guidance methods, the difficulty of the curriculum and the content of the curriculum meet their own expectations. A student with a high degree of professional identity goal establishment said that after learning programming courses in her freshman year, she wanted to further her studies in the technical field, so she had a strong willingness to learn, which virtually strengthened her sense of professional identity. It is found that when the above situation is different from their expectations, some students can quickly adjust their expectations or adopt appropriate methods to adapt to the new learning environment as soon as possible, while others have difficulty in doing so. This may be related to their growing environment, basic education, family education, personal character and other factors.

From the perspective of the training program, Chinese educational technology undergraduates have subjective understanding of the training program and curriculum setting. Some students have high satisfaction, while others think it cannot meet their own needs. A number of respondents with a low degree of professional identity said that with the gradual increase of the number and types of professional courses, it is difficult for them to lay a solid foundation for learning. They often feel confused and painful in the learning process, constantly doubt their ability, and gradually lose confidence in their major. At the same time, they also have many negative views on the major of educational technology, such as "the training objectives of the major are not clear", "the professional curriculum is very miscellaneous and the setting is unreasonable", "the curriculum content lags behind the development of the situation" and so on. But the study also found that two types of students-"striving for further education" and "switching lanes (turn to other majors)"-were more likely to take the initiative to learn about course content and seek guidance from teachers as they saw fit.

From the perspective of the social recognition of a major, students are positioned in the comparison between "their own expectations" and "the reality of the major", which is highly subjective and mainly influenced by teachers, classmates and other people around them. Most of the respondents said that they learned through communication with teachers and senior students that most of the undergraduates would find jobs as information technology teachers after graduation, and they could also engage in internet-related jobs if they had good programming skills.

External factors mainly include family expectations and constraints on students, the influence of classmates before enrollment (such as former partners and high school classmates), and the influence of classmates in the same major, etc. These factors determine students' future development direction and path choice to a certain extent.

\subsubsection{Whether Students Are Satisfied with the Present and Unwilling to Move Forward Is the Direct Cause Affecting Professional Identity}

From the original interview text and coding results, it can be seen that whether students are satisfied with the present and unwilling to move forward will di- 
rectly affect the establishment of professional identity of Chinese educational technology undergraduates. The secondary factors affecting "whether students are satisfied with the present and unwilling to move forward" can be divided into three aspects: anticipation and expectation, teaching guidance, and self-cognition.

From the perspective of anticipation and expectation, when students' original expectation (such as the occupation they can engage in after graduation, the type and social status of the occupation, the salary, etc.) is greatly different from the reality of educational technology major, they will have a great sense of loss, so they are more inclined to change the current situation. On the other hand, if the students' original expectation is to be an information technology teacher or there is some consistency with the professional training goal, they are more inclined to be satisfied with the current learning state. Teaching guidance mainly refers to the course teaching and course instruction provided by relevant teachers in the major. Under the same guidance, some students adapt well, while others do not, which gradually affects their degree of recognition of the major. Therefore, it is of great value to provide more diverse and abundant teacher guidance for the establishment of professional identity in student training. Self-cognition refers to a variety of self-positioning of students, such as self-efficacy, ability, character, specialty, interest, adaptability, interpersonal skills and other aspects, which affect whether students decide to change the current state and take action.

According to the research findings, regardless of the level of professional identity establishment, Chinese educational technology undergraduate students have experienced the following four critical periods: college entrance examination period, major transfer period, postgraduate entrance examination period and employment selection period. The dual effects of external factors and self-cognition greatly affect their choices in the four critical periods, especially for students with low degree of professional identity. First of all, when choosing college majors, some students blindly follow their parents' arrangements, lack independent ideas and fail to consider whether the major of educational technology is suitable for them. Secondly, in the freshman year turn professional, after a year and professional of friction, some students had to turn professional ideas, but didn't try for fear of failure, for example, there is a respondent who said he was "busy work students don't have time to prepare the turn professional exam", this belongs to the typical planning is not strong, for their own professional don't have a clear blueprint. Third, during the postgraduate entrance examination period, some students' expectations of their majors were dashed, and they were not satisfied with the current situation, so they chose to participate in the postgraduate entrance examination to actively seek change, but at this point, there are also some students were tired because of the heavy academic burden, so they chose to follow the trend the ideas of others. Finally, during the employment selection period, five educational technology undergraduates interviewed in this study with low level of professional identity goal establishment have one of them enrolled in another major, one of them chose to take the postgraduate entrance examination for another law major, one of them changed his 
career to become a mathematics teacher, and the remaining two still haven't found their development goals.

For students with a high degree of professional identity, they have strong resistance to setbacks, dare to try and make mistakes in the face of difficulties, and will actively respond to the goal once it is determined. First of all, they are independent and can selectively refer to their parents' opinions when filling out their applications. Secondly, students with a high degree of professional identity are able to think rationally and not be influenced by people around them when they change majors in the first year. Thirdly, in the third year of postgraduate entrance examination, students with a high degree of professional identity establishment have clear goals and clear plans. When it comes to disadvantages of professional development, they have an optimistic attitude and clear selfawareness. In the final employment choice period, they can also firmly make their own choice.

\subsection{Theoretical Framework of Professional Identity of Chinese Educational Technology Undergraduates}

From the above analysis, it can be seen that the two main factors affecting the establishment of professional identity of Chinese educational technology undergraduates are the consistency between students' expectations and reality and whether they are satisfied with the present and unwilling to move forward. Then, what is the main mechanism of the influence of these two factors on the professional identity of Chinese educational technology undergraduates? What is the correlation between these two factors? Through reading relevant literature and theories, as well as continuous comparison and selection, this study finally formed a theoretical interpretation framework for the establishment of professional identity of Chinese educational technology undergraduates (see Table 5).

Based on the theoretical interpretation framework of selective coding, this study divides the establishment of professional identity of Chinese educational technology undergraduates into four styles: normal development, swimming with the stream, studying hard for further education and seeking for change.

The first style is normal development (comfortable, cozy). If the undergraduates majoring in educational technology in China have basically the same expectation and reality of their major, and are satisfied with the current situation, they will have a high degree of professional identity, and thus embark on the

Table 5. Theoretical interpretation framework of professional identification of Chinese educational technology undergraduates.

\begin{tabular}{crc}
\hline $\begin{array}{l}\text { Whether the personality is } \\
\text { comfortable with status quo }\end{array}$ & Nos \\
Is expectation consistent with reality & No \\
\hline Yes & Normal development & Follow others \\
No & Study hard for further education & Seek for change \\
\hline
\end{tabular}


normal path of educational technology training, and are likely to work as information technology teachers or other related jobs in the future. The second type wants to study hard for further education. Such students' expectations of their major are basically consistent with the actual situation, but they prefer to be proactive. Therefore, they also establish a high degree of professional identity and choose to go out of the comfort circle to seek better professional development and improve themselves. In the future, they may choose to take postgraduate entrance examination or engage in higher demanding jobs. The third type of student is the drift type (confused, anxious). This kind of student has a large gap between their expectation of their major and the reality, and their character is content with the status quo, so it is difficult for them to establish professional identity. They lack recognition of their major but do not know how to change, so most of them can only follow the trend of study and job hunting, but they are prone to many failures, and finally they are confused about their current situation and even doubt their ability. The fourth type is seeking change. Undergraduate students of this kind of educational technology also have a large gap between their expectations and reality, but they don't want to be in a comfortable circle. Therefore, although their professional identity is relatively low, they will actively seek change and strive to pursue their goals. After graduation, they are likely to choose to change their major for postgraduate or engage in non professional work.

\section{Discussion and Prospect}

\subsection{Research Discussion and Suggestions}

This study takes educational technology undergraduates as the research object and reveals the deep reasons behind their professional identity construction process based on real interview materials. It is found that whether the students' expectation is consistent with the reality and whether they are satisfied with the status quo to interact with each other, thus affecting the establishment of professional identity of educational technology undergraduates. At the same time, it is also under the joint action of these two main factors that the substantive theoretical interpretation framework of educational technology undergraduates' professional identity is established. Therefore, in order to improve students' professional identity, on the one hand, students need to change their existing understanding of the major, and on the other hand, colleges, teachers and parents need to work together to create a more harmonious environment for students in terms of curriculum setting and career planning guidance.

First, teachers should help students establish objective professional cognition. It is found that students with a low degree of professional identity construction almost view the educational technology major with prejudice. As a result, they only see the disadvantages of their major and ignore its advantages. This subjective prejudice always affects students' study life, and as time goes by, students lose confidence in their major and even lose their enthusiasm for learning. 
However, students with a high degree of professional identity construction can hold an objective attitude towards their major. They believe that we should consider all aspects, accept the advantages of the major and objectively look at the disadvantages of the major. They also believe that if they are constantly resistant, they tend to blame the failure of professional identity building on professional weaknesses. Most of the students' understanding of the major comes from external influence. What teachers say and do in class represents their attitude towards the major. Therefore, whether in life or study, when students have cognitive deviation, teachers should patiently explain to students, reasonably guide students to establish an objective professional identity.

Second, colleges should rationalize the curriculum. Grounded analysis of interview data shows that students generally believe that programming courses are difficult and specialized courses are not in-depth studied. Therefore, it is necessary for colleges to constantly improve the training program, rationally allocate the course order, and give students more space to choose. Let students quickly adapt to the major on the basis of an in-depth understanding of the major, so as to successfully establish the professional identity. Programming courses of different difficulty levels should be reasonably arranged in each grade. In addition, more practical courses should be set up so that students can apply knowledge to practice, so as to better experience the difference between the classroom and practical application.

Third, the university and teachers should strengthen the guidance of career planning. Research shows that students who fail to establish professional identity are vague about their future career roles at the beginning of college and do not start to think about planning until near graduation. Students with successful professional identity establishment actively seek help from senior students and teachers, learn professional employment information through multiple channels, and participate in activities and competitions held by the school to explore their advantages. Therefore, the university can regularly carry out career planning theme lectures, invite all kinds of graduates to exchange learning and employment experience, enhance students' awareness of career planning. In addition, in the study of professional courses, teachers should share the cutting-edge direction of the industry, provide guidance for students' employment, so that students can keep abreast of the latest news.

Fourthly, teachers and parents should cultivate students' initiative and improve their self-confidence. The dual effects of external factors and self-cognition greatly affect students' judgment. In daily study and life, students should be given more space to think and make more independent choices. When filling in the major, teachers and parents should let students understand the major positioning, and give more positive and objective guidance. In addition, teachers can provide relevant professional guidance, remind students not to blindly follow the major transfer, and encourage students to get out of their comfort zone by participating in activities. 


\subsection{Research Limitations and Prospects}

The research also has the following deficiencies. First of all, the original text of this study was obtained through purposive sampling and an in-depth interview. Although the sample has reached the "data saturation", whether it has reached the "theoretical saturation" remains to be discussed. Secondly, due to the impact of the epidemic, an online voice was used in interviews. The interviewer could not see the expressions and movements of the interviewee and could not adjust them in time for further communication. Finally, the author's limited personal ability and lack of experience in qualitative research may lead to insufficient in-depth research results. In the future, more samples will be selected for faceto-face interviews, so as to conduct in-depth empirical research on issues related to the professional identity of educational technology undergraduates.

\section{Funding}

This study was supported by the Jiangsu Provincial Superior Discipline Construction Project (PAPD).

\section{Conflicts of Interest}

The authors declare no conflicts of interest regarding the publication of this paper.

\section{References}

An, Q., \& Jia, X. M. (2006). The Professional Identity of College Counselor. Chinese Journal of Clinical Psychology, 14, 203-206.

Chen, X. M. (1999). Grounded Theory: Its Train of Thought and Methods. Educational Research and Experiment, 58-63+73.

Chen, X. M. (2015). Exploration on the Application of Grounded Theory in Chinese Education Research. Peking University Education Review, 13, 2-15+188.

Chen, Y., Liang, Y., \& Qiang, L. J. (2008). The Comparative Research of the Professional ldentity of Undergraduate Students Major in Preschool Education. Studies in Early Childhood Education, 21-24.

Han, Y., \& Tang, W. H. (2011). Investigation and reconstruction of professional beliefs of students majoring in educational technology in Local Universities. Modern Educational Technology, 21, 52-55+102.

Levinson, E. M., Ohler, D. L., Caswell, S., \& Kiewra K. (1998). Six Approaches to the Assessment of Career Maturity. Journal of Counseling and Development, 76, 475-482. https://doi.org/10.1002/j.1556-6676.1998.tb02707.x

Li, J. Y., Bai, J. H., \& Bao, Y. Y. (2016). The Status Quo Investigation of Education Technology Undergraduates' Professional ldentity-Hebei Normal University of Science and Technology as an Example. Office Informatization, 21, 48-51.

Liu, X. J. (2018). A Study on the School Factors Influencing the Professional Identity of Teachers in Educational Technology Majors. Master Thesis, Qufu Normal University, Qufu, China.

Strauss, A., \& Corbin, J. (1990). Basics of Qualitative Research: Grounded Theory Procedures and Techniques. Sage, 61-142, 84-93, 96-98, 99, 163.

Tahim, A. (2015). Who are We? A Qualitative Evaluation of Trainees' Perspectives on 
Professional Identity in Oral and Maxillofacial Surgery. Perspectives on Medical Education, 4, 33-38. https://doi.org/10.1007/s40037-015-0156-1

Wang, D. M., \& Liu, Y. C. (2007). Survey on Professional Identity of Postgraduate Students. China Higher Education Research, 8, 18-22.

Wang, G., Liao, J., \& Zhang, Z. H. (2011). Investigation on the Professional Attitudes of Undergraduates from the Educational Technology Major. Journal of Tonghua Normal University, 81-83+99.

Wang, X. H. (2003). Analysis on Objective Position and Competent Structure of Educational Technology Speciality in Higher Vocational Education. Vocational and Technical Education, 24, 36-39.

Zhu, S. Q., \& Liu, M. X. (2018). An Empirical Study on Major ldentity of Students Majored in Educational Technology. Modern Distance Education, 35-44. 